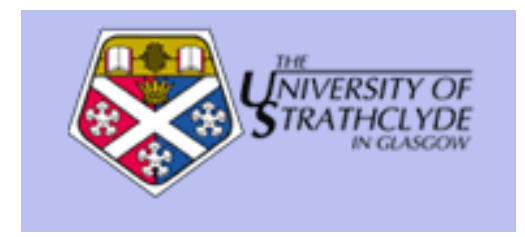

Bradley, N.A. and Dunlop, M.D. (2005) An experimental investigation into wayfinding directions for visually impaired people. Personal and Ubiquitous Computing, 9 (6). pp. 395-403. ISSN 1617-4909

http://eprints.cdlr.strath.ac.uk/2660/

This is an author-produced version of a paper published in Personal and Ubiquitous Computing ISSN 1617-4909.

This version has been peer-reviewed, but does not include the final publisher proof corrections, published layout, or pagination.

Strathprints is designed to allow users to access the research output of the University of Strathclyde. Copyright (c) and Moral Rights for the papers on this site are retained by the individual authors and/or other copyright owners. Users may download and/or print one copy of any article(s) in Strathprints to facilitate their private study or for non-commercial research. You may not engage in further distribution of the material or use it for any profitmaking activities or any commercial gain. You may freely distribute the url (http://eprints.collr.strath.ac.uk) of the Strathprints website.

Any correspondence concerning this service should be sent to The Strathprints Administrator: eprints@cis.strath.ac.uk 


\title{
An Experimental Investigation into Wayfinding Directions for Visually Impaired People
}

\author{
Nicholas A. Bradley, Mark D. Dunlop \\ Department of Computer and Information Sciences \\ University of Strathclyde, Glasgow, Scotland, G1 1XH, UK \\ Tel: +44 (0) 141552 4400, Fax: +44 (0) 1415525330 \\ E-mail: \{Nick.Bradley, Mark.Dunlop\}@cis.strath.ac.uk
}

\begin{abstract}
In recent years, there has been an escalation of orientation and wayfinding technologies and systems for visually impaired people. These technological advancements, however, have not been matched by a suitable investigation of humancomputer interaction (e.g. designing navigation aids for people who form different cognitive maps for navigation). The aim of this study was to investigate whether a group of sighted participants and a group of visually impaired participants experience a difference in mental and physical demands when given two different sets of verbal instructions directing them to four landmarks. The content of the first set of instructions was proportioned to route descriptions derived from sighted people, and the second set proportioned to descriptions derived from visually impaired people. The time taken to reach landmarks and the number of deviations provided the objective assessment and a NASA-Task Load Index questionnaire provided an indication of participants subjective perception of workload. The results revealed that instructions formed from visually impaired people resulted in a lower weighted workload score, less minor deviations, and quicker times for visually impaired participants. In contrast, these instructions were found to cause a higher weighted workload score for sighted participants. The results are discussed in relation to the issue of personalisation of mobile context-aware systems for visually impaired people.
\end{abstract}

\section{Introduction}

There are approximately 135 million visually impaired people worldwide [1]. In recent years, a plethora of orientation and wayfinding technologies have been designed to enhance and maintain the independence of this community. However, despite recent technological advancements, there appears to be a paucity of Human Computer Interaction (HCI) research. For instance, the mobile contexts in which visually impaired people interact and the cognitive maps that they form to orientate and navigate are areas not fully addressed in existing research. Although involving visually impaired people in experiments can be difficult, Maeda et al [2], for instance, describe how their evaluation of a GPS-based guidance system involved asking sighted people to wear blindfolds and 'behave as if temporarily blind'. May [3] illustrates the danger of this approach when considering the mental imaging skills of congenitally blind people (e.g. how is environmental information learnt, processed, and used when attempting to make sense of the environment?).

Further examples concern the use of speech output as the primary (and often only) source of conveying information to the user (e.g. [4], [5]). Franklin [6] highlights the difficulties of interpreting spatial relations from common speech, Pitt \& Edwards [7] indicate how speech interfaces are slow to use and more demanding on memory than vision or touch, and Strothotte et al [4] demonstrate how headphones used to transmit audio messages may mask/distort sounds in the environment which are necessary for avoiding hazards. Ross \& Blasch [8] found that the best interface combined tactile cues using a tapping interface with improved speech output.

\subsection{Wayfinding Technologies}

Broadly speaking, all research can be classified into navigational assistance for (i) indoor environments (e.g. [9]), (ii) outdoor environments (e.g. [4, 10]), and (iii) a combination of both (e.g. $[5,11])$. In relation to outdoor environments, Petrie [12] distinguishes between 'micro-navigation' technologies, which provide assistance through immediate environment, and 'macro-navigation' technologies, which provide assistance through the distant environment. For instance, ETAs (Electronic Travel Aids) such as obstacle avoidance systems (e.g. Laser Cane [13] and ultrasonic obstacle avoiders [14]) have been developed to assist visually impaired travellers for micronavigation. Whereas, Global Positioning Systems (GPS) and Geographical Information Systems 
(GIS) have been used to assist macro-navigation. Examples include the MOBIC Travel Aid [4], Arkenstone system [15] \& Personal Guidance System [5]. Radio Frequency (RF) beacons have also been used to assist navigation for both micro and macro navigation [16].

Navigation through indoor environments, on the other hand, has been developed using similar systems. As GPS is ineffective inside buildings, most systems depend on relative positioning using sensors such as digital tags, active badge, accelerometers, temperature, photodiodes and beacons [17, $18,19]$.

\subsection{Human Wayfinding and Cognitive Maps}

Human wayfinding consists of both sensing the immediate environment for obstacles and hazards, and navigating to remote destinations beyond the immediately perceptible environment [20]. Navigation therefore involves updating one's orientation and position; a process involving position-based navigation, velocity-based navigation, and acceleration-based navigation (all of which are described by Loomis et al [20]). Visually impaired people are therefore at a huge disadvantage in unfamiliar routes, as they 'lack much of the information needed for planning detours around obstacles and hazards, and have little information about distant landmarks, heading and self-velocity’ [20].

Cognitive mapping research focuses on how individuals acquire, learn, develop, think about and store data relating to the everyday geographic environment (e.g. encoding locations, attributes and landmark orientations to navigate) [21]. Jonsson [22] describes how maps can change for one particular area depending on the (i) time of day (i.e. day/night), (ii) season (e.g. summer vs. winter), and (iii) direction of travel (travelling the same route forward or back).

A number of theories (e.g. landmark-based learning strategies and route-based strategies) and mechanisms (e.g. images, dual coding, genetic coding, etc.) have been advanced to account for how knowledge is learned, stored, and structured. However, the unique strategies and mechanisms used by visually impaired people have not been given sufficient investigation in current research [23]. Kitchen \& Jacobson [24] argue that cognitive mapping research could reveal 'what spatial information should be given to visually impaired pedestrians, in what form and at which particular locations'. Different forms of visual impairment might also impact on cognitive map development, as illustrated in Figure 1 (parts a-d). Someone experiencing a loss of central vision (part b) would perhaps find reading text (e.g. road signs) extremely difficult, whereas someone with only one half of their field of vision (part d) would possibly be more dependent on information within the side that was lost.

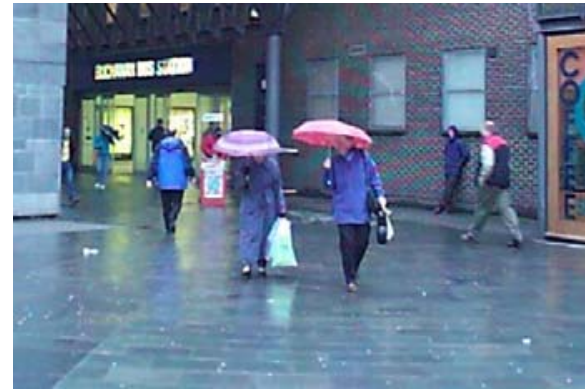

(a) Normal vision

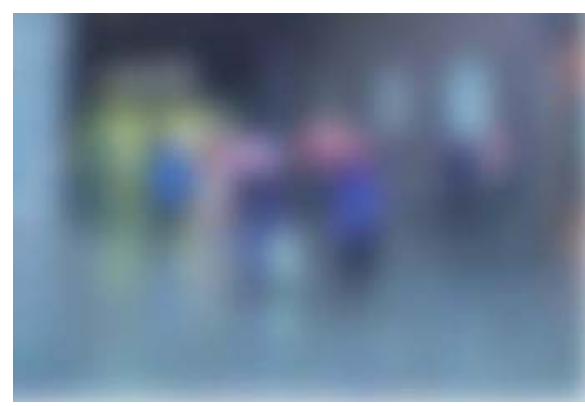

(c) Possible effect of advanced cataract

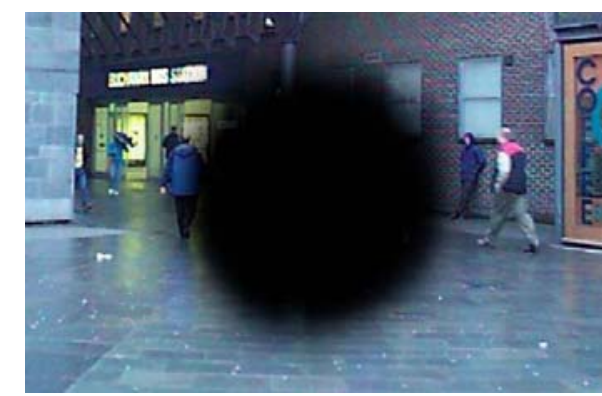

(b) Loss of central vision (this can be caused by macular degeneration)

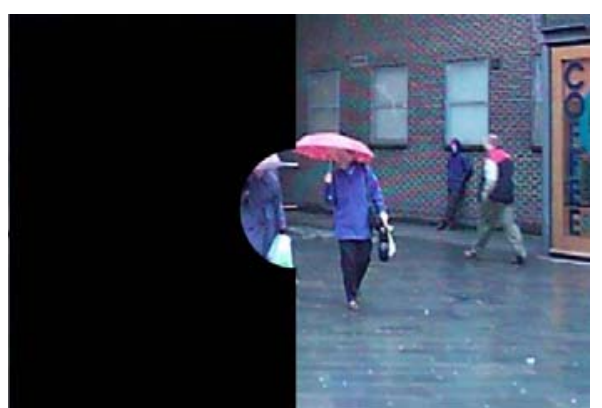

(d) One half of the field of vision lost (may be due to stroke or head injury)

Fig. 1. Pictorial representations of different visual impairments. 


\subsection{Context-aware Mobile Computing}

Many researchers state that user-interface interaction in mobile settings is an area that requires more investigation [37]. Zetie [25] illustrates how there is a need to understand a user's context, with respect to how people behave, make decisions, select goals, and interact with other people and objects. Schilit et al [35] believe that the important aspects of a user's context are 'where you are, who you are with, and what resources are nearby'. Dey \& Abowd [26] state that an understanding of context can 'increase the richness of communication in Human-Computer Interaction (HCI) making it possible to produce more useful computational services'. Investigations of context, however, reveal that existing orientation and wayfinding technologies only support one aspect of a user's context (i.e. local vs. distant and indoor vs. outdoor). In order to facilitate independent mobility of visually impaired travellers it is necessary to combine those technologies.

This is the premise of context-aware computing, which was defined by Schilit \& Thiemer [36] as software that 'adapts according to its location of use, the collection of nearby people and objects, as well as changes to those objects over time'. Essentially, information is adjusted in order to suit the user's current task, situation and environment. Aspects of the user's context could therefore be inferred, minimising traditional user-computer interaction and allowing visually impaired people to focus more exclusively on hazard identification and environmental learning [8, 27]. Making a computer more aware of the user's context unravels new and potentially enhanced levels of user support, which have been categorised by a number of researchers. Pascoe [28] proposes four generic categories of context-aware capabilities, shown in Table 1.

Table 1. Capabilities of context-aware applications

\begin{tabular}{|l|l|}
\hline \multicolumn{1}{|c|}{$\begin{array}{c}\text { Context-aware } \\
\text { capabilities }\end{array}$} & \multicolumn{1}{c|}{ Definition } \\
\hline Contextual sensing & $\begin{array}{l}\text { Application senses environmental states and presents them to the user (e.g. a } \\
\text { GPS receiver takes in a location, compares it to a digital map, and then } \\
\text { informs the user of their location). }\end{array}$ \\
\hline $\begin{array}{l}\text { Contextual } \\
\text { adaptation }\end{array}$ & $\begin{array}{l}\text { Application leverages contextual knowledge by adapting its behaviour to } \\
\text { integrate more seamlessly with the user's environment (e.g. re-routing a } \\
\text { visually impaired traveller in order to avoid excavation work). }\end{array}$ \\
\hline $\begin{array}{l}\text { Contextual resource } \\
\text { discovery }\end{array}$ & $\begin{array}{l}\text { Application discovers other resources within the same context as itself and } \\
\text { exploits these resources while they remain in the same context (e.g. bus } \\
\text { timetables could be downloaded from bus stops and used to inform the user of } \\
\text { when their next bus home will arrive). }\end{array}$ \\
\hline $\begin{array}{l}\text { Contextual } \\
\text { augmentation }\end{array}$ & $\begin{array}{l}\text { Application augments the environment with additional information (e.g. } \\
\text { visually impaired people could leave messages about potential hazards at } \\
\text { specific locations along a route for other visually impaired people). }\end{array}$ \\
\hline
\end{tabular}

The GPS systems described in 1.1 are mostly centred on contextual sensing. Context-aware computing therefore has the potential to provide visually impaired people with more personalised and task specific information. In order to realise the capabilities described in Table 1, the application must acquire useful information about the user. Examples of user information used by context researchers, as well as the technologies used to acquire it (shown in brackets), include:

- Indoor and outdoor location of the user (e.g. GPS, Active badge, mobile phone cells);

- Detection of nearby objects, such as printers, other mobile devices, etc. (e.g. ultrasonic transducers, Bluetooth and Infrared sensors);

- Localised transmission of information about environment (e.g. RF beacons);

- $\quad$ Speed of movement and vibration - walking vs. driving (e.g. accelerometers sensors);

- Orientation of body - upright or lying down (e.g. electronic compass);

- Outside temperature, ambient light levels, and noise levels (e.g. temperature sensors, photodiodes, omni-directional microphones);

- Heart rate, body temperature, blood pressure, tone of voice, etc (e.g. physiological sensors)

- Time of day, week, month, season, and year (e.g. built in clock);

- User preferences (e.g. customised application settings);

- Social and business arrangements, activities, etc (e.g. personal diaries);

- Available resources - weather forecasts, train and bus timetables, etc (e.g. web-based servers);

- Face recognition to detect surrounding people (e.g. camera technology and image processing). 
As illustrated in previous sections, multi-disciplinary investigations must be used to investigate how this context data should be used and interpreted when attempting to transmit meaningful information to the user $[27,29,33]$. The study presented in this paper concentrates on the issue of personalisation of context-aware mobile systems (e.g. how should information be adjusted for different types of users or user groups?).

\subsection{Tailoring Information for Visually Impaired People}

LaGrow \& Weessies [30] demonstrate how orientation involves gathering and interpreting available sensory information which may be visual, auditory, kinaesthetic, tactile, thermal and/or olfactory. In the absence of vision, information from other sensory sources becomes crucial. However, existing travel databases do not provide information which would be of use to visually impaired people, such as road widths; differences of road textures; direction of traffic flow; contrasting environmental smells and sounds; people identification; and temporary, unexpected features (e.g. overhanging branches) [2, 3, 5, 9, 11].

Several levels of detail should also be available in a realistic range of situations [2, 4, 5, 9]. Strothotte et al [4] differentiate between (i) 'basic information' which includes travel direction, nearest crossing, and any known obstacles, (ii) ‘detailed information’ which consists of pre-journey plans, and (iii) 'transport information’ which includes nearest bus stops, stations, and taxi ranks.

Existing wayfinding systems also do not differentiate between information required on foot versus information required in vehicles. Consequently, when travelling on conveyances, visually impaired people are deprived of information including road signs, landmarks, and identification of stations [3].

\subsection{Previous Research and Study Purpose \& Aim}

This study is based on the results of two previous studies that involved using cognitive mapping research (discussed in section 1.2) to investigate differences in how sighted people [31] and visually impaired people [27] use landmarks to navigate. Route descriptions from both studies were categorized, resulting in the eleven classes of contextual information shown in Table 2 . The proportion of words/phrases used across the route descriptions of sighted and visually impaired participants are shown for each contextual category.

Table 2. Classes of contextual information used by sighted and visually impaired participants

\begin{tabular}{|l|l|c|c|}
\hline $\begin{array}{c}\text { Class of contextual } \\
\text { information }\end{array}$ & \multicolumn{1}{|c|}{ Example } & $\begin{array}{c}\text { \% Used } \\
\text { Sighted }\end{array}$ & $\begin{array}{c}\text { \% Used Vis } \\
\text { Imp }\end{array}$ \\
\hline 1. Directional & Left/right, north/south & 37.4 & 30.1 \\
\hline 2. Structural & Road, monument, church & 11.5 & 20.1 \\
\hline 3. Environmental & Hill, river, tree & 1.6 & 2.9 \\
\hline 4. Textual-structural & Border's bookshop, Greaves Sports & 9.9 & 1.2 \\
\hline 5. Textual-area/street & Sauchiehall St., George Sq. & 15.6 & 2.7 \\
\hline 6. Numerical & First, second, 100m & 5.0 & 7.5 \\
\hline 7. Descriptive & Steep, tall, red & 10.8 & 23.8 \\
\hline 8. Temporal/distance & Walk until you reach...or just before you get to... & 8.2 & 5.1 \\
\hline 9. Sensory & Sound of cars passing or smelling a bakery & 0 & 4.4 \\
\hline 10. Motion & Cars passing, doors opening & 0 & 0.8 \\
\hline 11. Social contact & Asking people or using a guide dog for help & 0 & 1.4 \\
\hline
\end{tabular}

The results revealed that sighted and visually people vary individually and collectively within and across groups. When comparing groups, visually impaired participants used (i) information within three additional categories of information relating to sensory, motion, and social contact, (ii) considerable less textual-structural and textual-area/street information, and (iii) considerably more contextual information generally, especially in structural and descriptive classes. Within the sighted group, younger participants used significantly more textual-structural landmarks than older participants who used more textual area/street based landmarks. There was also variation within the visually impaired group.

The aim and purpose of this study was, firstly, to design two sets of proportioned verbal directions based upon table 2, and, secondly, to use these verbal directions to guide different groups of visually impaired and sighted participants to pre-determined landmarks. The purpose was to investigate whether participants experience differences in perceived workload. The hypothesis is therefore that 
there will be a difference in workload between sighted and visually impaired groups, when given proportioned verbal instructions from sighted people's route descriptions versus proportioned instructions from visually impaired people's route descriptions. The overall purpose of this study was to investigate the issue of personalisation of mobile navigation systems, which remains insufficiently addressed in context-aware research and development.

\section{Methodology}

After a pilot study, 16 participants (8 sighted people and 8 visually impaired people - both groups were also gender balanced) who were resident in Greater Glasgow and aged between 23 to 73 were recruited for the study. Although it was hoped to recruit more visually impaired people, locating them proved to be problematic. Types of visual impairment experienced by participants included advanced glaucoma, macular degeneration (loss of central vision), and blindness (or only some light perception). Three participants had been visually impaired since birth, while five have been impaired for 4 - 35 years respectively. All participants used either a guide dog or white cane.

The experiment involved asking participants to walk to four pre-determined landmarks, all of which were situated in Glasgow city centre in order to simulate a typical contextually rich city-centre environment (a researcher accompanied each participant for safety reasons). Participants were given pre-recorded verbal directions via a Minidisk to navigate to each landmark, all of which took approximately 10 minutes to reach. Verbal directions designed from sighted participants' route descriptions from the last study were used to guide participants to two of the landmarks (condition 1), while verbal directions designed from visually impaired participants' route descriptions were used to guide participants to the other two landmarks (condition 2). The order of when each condition was given was randomised. By using 'Wizard of Oz' style techniques, the researcher controlled the timing of verbal messages. Subsequently, there may have been minor differences in message timing between each experiment though this method was still considered to be more accurate than current technological alternatives (e.g. poor accuracy of GPS in built-up city-centre environments). It should also be noted that despite the problems of using speech output as described in Section 1, the purpose of this study was to investigate information content rather than the process of transmitting information.

The time taken to reach landmarks and the number of deviations (i.e. minor - slight veering; and major deviations - wrong direction) provided the objective assessment. The timer was stopped when deviations occurred and whilst waiting at traffic lights, and then re-started once re-routed or when crossing the road was initiated - in doing so provided more accurate data. Questions about deviations as they occurred and post-trip questionnaires formed the subjective assessment.

The design of verbal messages was a complex task. Firstly, a researcher in the department who was unknowing of the experiment was asked to walk to each of the landmarks and while doing so verbally describe the environment in relation to the eleven contextual categories. This information was then loosely attributed to each of the conditions by using the proportions in Table 2. For each landmark, an equal number of messages was used for condition one and condition two (on average, this amounted to 15 messages). Messages were also structured in accordance to Pitt \& Edwards (1996) principles of speech-based interfaces.

\section{Results}

The study involved two conditions: condition 1 consisted of verbal directions designed from the sighted participants' route descriptions, whereas condition 2 consisted of verbal directions designed from visually impaired participants' route descriptions. The length of time taken by participants to reach each landmark (Lan) when being given either condition 1 or 2 is shown first. Following this, the number of, and explanation given for, minor and major trip deviations are presented and described.

\subsection{Mean Times for each Condition}

The results presented in Figures 2 and 3 illustrate the comparison between condition 1 and condition 2 mean times for both sighted and visually impaired participants. Figure 4 illustrates the differences between condition 1 and condition 2 mean times for both groups. 


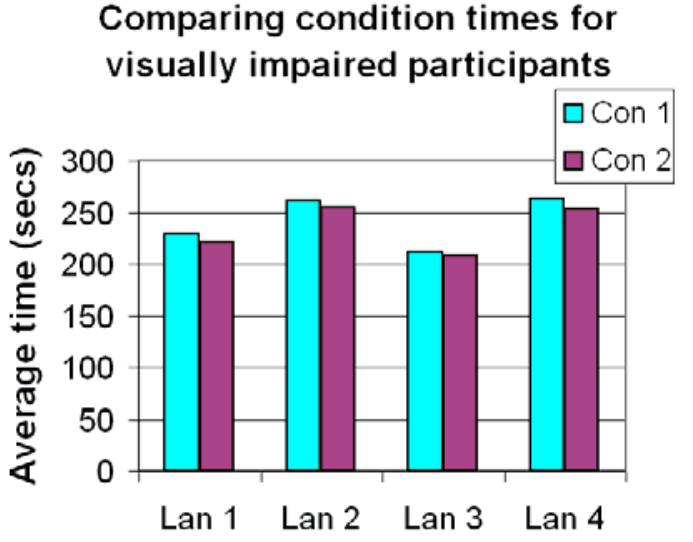

Fig. 2. Comparing mean times for conditions 1 \& 2 for visually impaired

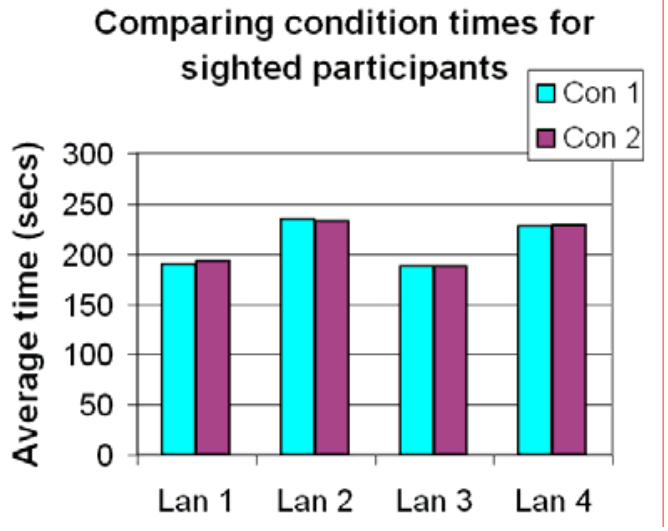

Fig. 3. Comparing mean times for conditions 1 \& 2 for sighted participants.

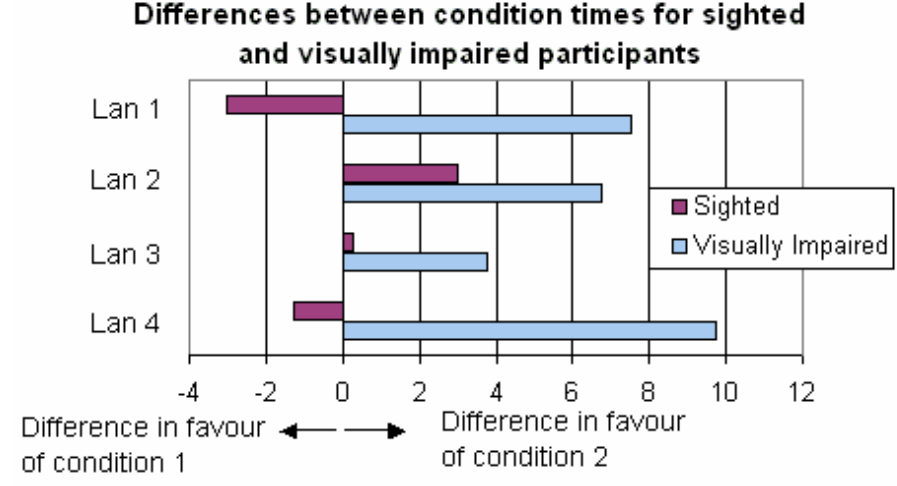

Difference between average times (secs)

Fig. 4. Differences between condition times for both sighted and visually impaired participants

The key findings of Figures 2, 3, and 4 are as follows:

- Visually impaired participants reached landmarks significantly quicker when given information from condition two (using a two-tailed parametric related $t$-test, $t=5.599>3.182$, at $\mathrm{p}=0.05$ ). In other words, messages which contained a reduced amount of textual-structural and textual area/street information, and which incorporated sensory, motion and social contact information, resulted in visually impaired participants reaching landmarks quicker in comparison to messages which consisted of an increased amount of textual-structural and textual area/street information. There was not a significant difference between mean condition times of sighted participants (using a two-tailed parametric related t-test, $\mathrm{t}=-0.196<3.182$, at $\mathrm{p}=0.05$ ).

- Figure 4 shows that the difference of mean times were all in favour of condition 2 for the visually impaired group, and also for two of the landmarks for the sighted group.

- Visually impaired participants took longer to reach all landmarks for both conditions than sighted participants. Using a two-tailed parametric independent t-test, this result was significant $(\mathrm{t}=2.482>2.145$, at $\mathrm{p}=0.05)$.

\subsection{Deviations from Pre-determined Route}

No minor deviations were made by sighted participants in either condition, whereas, visually impaired participants made 17 in condition 1 and 13 in condition 2. Explanations for those minor deviations included: (i) 'slight curvatures in the road made it difficult to remain correctly positioned, and (ii) 'when I crossed the street there were less surrounding features for which I could use to keep aligned'.

With respect to major deviations, sighted participants made 2 major deviations in condition 1 , and 1 in condition 2. Visually impaired participants, on the other hand, made 1 major deviation in condition 1 , and none in condition 2 . The explanation given by both sighted and visually participants were that instructions had been misunderstood. 


\subsection{Post-experiment Opinions}

The post-trip questionnaire provided an opportunity for participants to reveal any issues regarding the experiment, the information they received, or wayfinding in general. The main issues that were highlighted are shown in Table 3.

Table 3. Post-trip comments given by sighted and visually impaired participants

\begin{tabular}{|l|l|}
\hline Visually impaired participants' comments & \multicolumn{1}{|c|}{ Sighted participants' comments } \\
\hline $\begin{array}{l}\text { (i) Five participants expressed how not } \\
\text { enough detail in the immediate and } \\
\text { temporary surrounding environment was } \\
\text { given to them in condition 1. }\end{array}$ & $\begin{array}{l}\text { Four participants found condition 2 messages } \\
\text { too detailed, especially when crossing at } \\
\text { traffic lights, and consisting of information } \\
\text { that was not of use to them (such as sounds, } \\
\text { smells, etc.). }\end{array}$ \\
$\begin{array}{l}\text { (ii) Four remarked how information on sounds } \\
\text { and smells within condition 2 provided } \\
\text { them with a better orientation of the } \\
\text { environment. }\end{array}$ & $\begin{array}{l}\text { (ii) Two participants described how there were } \\
\text { situations where controlling the level of detail } \\
\text { would have been advantageous. }\end{array}$ \\
\hline
\end{tabular}

\section{Workload Assessment}

Once participants had reached each landmark they were asked to complete a NASA-TLX (Task Load Index) questionnaire (Hart \& Staveland, 1988). This was to assess their perceived level of workload using six dimensions:

- Mental Demands (MD): The mental and perceptual activity required (e.g. thinking, calculating, deciding, remembering, looking, etc).

- Physical Demands (PD): The physical activity required (e.g. pulling, pushing, turning, controlling, etc.)

- Temporal Demands (TD): The time pressure perceived due to the rate or pace at which tasks or task elements occurred.

- Own Performance (OP): The estimation of the success by which task goals were accomplished.

- Effort (EF): The level of physical and mental work required to accomplish a level of performance.

- Frustration (FR): The level of discouragement, irritation and annoyance versus gratification, contentment, and complacency felt during the task.

Mental, Physical, and Temporal Demands concern the demands imposed on the participant, whereas the other three to the participant-task interaction.

The initial step involved listing every paired combination of workload dimensions in order to carry out a pair-wise comparison. Participants were asked to indicate which member of each pair provided the most significant source of workload variation, thereby providing a tally (or weighting) for each dimension.

Next, participants were asked to provide a magnitude rating using a five-point scale for each dimension, which was multiplied with the corresponding weighting. This provided a weighted score for each dimension. Figures 5 and 6 illustrate the average weighted scores for each condition for sighted and visually impaired participants. Whereas, Figures 7 and 8 show the comparison between both groups for each condition.

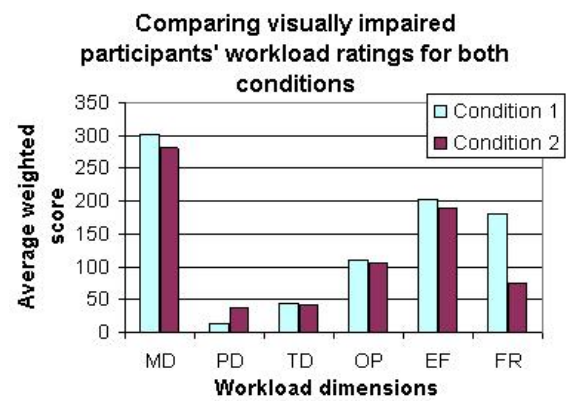

Fig. 5. Comparing visually impaired participants' ratings for condition 1 and 2

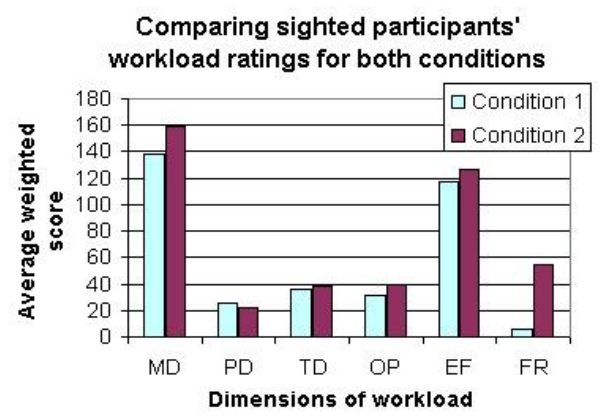

Fig. 6. Comparing sighted participants’ ratings for condition 1 and 2 


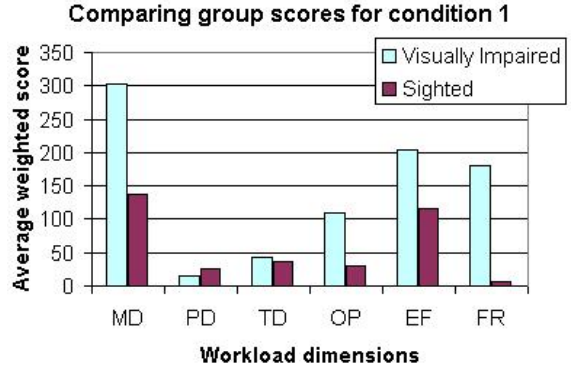

Fig. 7. Comparing sighted and visually impaired participants' scores for condition 1.

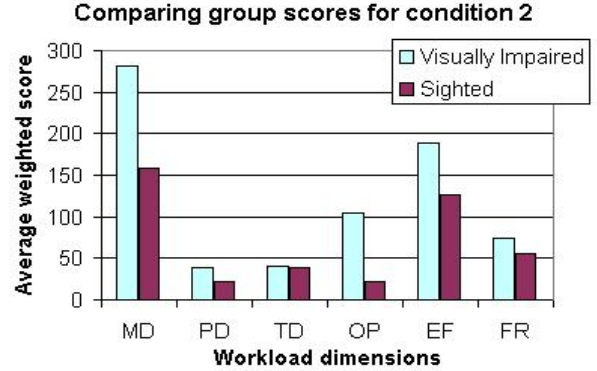

Fig. 8. Comparing sighted and visually impaired participants' scores for condition 2

The results reveal, as shown in Figure 5, that visually impaired participants found condition one caused a higher demand mentally and temporally, a higher level of effort and frustration, and a lower sense of performance success. Whereas, Figure 6 illustrates how sighted participants found condition two to cause a higher demand mentally and temporally, a higher level of effort and frustration, and a lower sense of performance success. To support this finding, visually impaired participants' mean Weighted Workload (WWL) scores (the sum of weighted scores across all workload dimensions divided by sum of weights) were 56.7 for condition 1 , and 49 for condition 2, whereas, sighted participants were 23.6 for condition 1 and 28.2 for condition 2. These results also reveal that the visually impaired group had higher WWL scores for both condition 1 and 2 . This corresponds to the results presented in Figures 7 and 8, which show how visually impaired participants have a higher weighted score for all condition dimensions (except PD in condition 1).

The last finding from Figures 5 to 8, is that MD and EF provide the greatest source of workload, and PD the least, within both conditions for both groups.

\section{Future developments}

Our next study will involve investigating the construction of cognitive maps by people with different visual impairments in order to contribute further to the issue of personalisation of contextaware navigation services for visually impaired people. We plan to build a Java application to transmit personalised information to different groups of visually impaired travellers. We are exploring two separate designs in order to accomplish this:

(i) an application representing a centralised server which would use user information sent from a combined GPS-enabled IPAQ and mobile phone (e.g. a visually impaired person's GPS readings and their type of visual impairment) in order to select and transmit route instructions. Instructions could be transmitted either textually (using a text-speech application) or verbally (by calling the user with automated verbal messages).

(ii) an application which would run locally on the user's GPS-enabled IPAQ and play audio files, via a set of headphones, whenever a visually impaired traveller enters pre-specified distance thresholds along a route.

The study may also involve investigating different contexts (i.e. indoor vs outdoor) and different modes of travel (e.g. train, bus, walking, etc). Lastly, this entire process will be designed using our user-centred and multidisciplinary design framework for context-aware applications [33], which has been designed to compliment software-orientated frameworks such as Dey \& Adowd's Context ToolKit [34].

\section{Discussion and conclusions}

Two previous studies involved using cognitive mapping research (discussed in section 1.2) to investigate differences in how sighted people [31] and visually impaired people [27] use landmarks to navigate. The results of these studies were used to design proportioned verbal instructions from sighted people's route descriptions (condition 1) and proportioned instructions from visually impaired people's route descriptions (condition 2). In this study different sets of visually impaired and sighted participants were asked to walk to pre-determined landmarks when being given either condition.

The results support the original hypothesis that there would be a difference in workload between groups. Visually impaired participants were less frustrated, and required less mental and overall effort when being guided by condition 2 directions consisting of a reduced amount of textual-structural and textual area/street information, and incorporated sensory, motion, and social contact information. This finding is consistent with the objective assessment, which showed that visually impaired people 
reached landmarks significantly quicker when given condition 2 directions. The sighted group, on the other hand, displayed little evidence of being faster for either condition, but did demonstrate a greater mental workload within condition 2, especially for Frustration, Mental Demands, and Effort.

Since condition 1 contained messages predominantly consisting of building/street names, the explanation for these results could be due to the fact that there was insufficient information for visually impaired people to navigate through the immediate or local environment (a view supported by more than half of the visually impaired group). This would explain why the visually impaired group made more minor deviations when being given condition 1 directions. As also observed by LaGrow \& Weesies [30], existing travel databases need to be augmented for visually impaired travellers in order to incorporate more meaningful information. While the results of our study have contributed to cognitive mapping research in terms of the use of landmarks by people with visual impairments, more research is needed to investigate possible differences between visual impairments (as depicted Figure 1). The results also show that, although significantly less than condition 1 , the workload value for condition 2 was also quite high. We plan to investigate this issue further as well as continuing other work exploring differences between normally sighted people, such as cultural differences (e.g. people from different cultural backgrounds may use different landmarks to navigate) and gender differences.

As discussed earlier, context-aware systems offer huge potential for visually impaired people not just for navigation but for other mobile tasks too [11]. They have the ability to augment the visually impaired travellers knowledge of the environment beyond the immediate environment. By using a combination of technologies, information within a user's context can be sensed, adapted, discovered and augmented including both dynamic and fixed environmental features within the micro- and macro-environment. The success of such systems, however, will be dependent on how well information and services are personalised to the needs of the user. The results of this study have provided a considerable contribution to this issue by demonstrating that sighted and visually impaired people differ in their use of landmarks to orientate and navigate.

To conclude, the results of the study have revealed that visually impaired people rate their level of workload less when messages have a reduced amount of textual-structural and textual area/street based information, and incorporate sensory, motion, and social contact information. This is further supported by an objective assessment, which revealed the visually impaired group were faster at reaching landmarks when given this information. Future work will involve investigating the construction of cognitive maps by people with different visual impairments in order to contribute further to the issue of personalisation of context-aware navigation services for visually impaired people.

\section{Acknowledgements}

This work is partly supported by the EU funded project GLOSS (Global Smart Spaces). We would like to thank the Glasgow and West of Scotland Society for the Blind for assisting with the study, and the participants who kindly took part.

\section{References}

1. Balliwalla, Low Vision - Assessment and Aids, Bombay Hospital Journal http://www.bhj.org/journal/2002_4403_jul/md_397.htm, 2002.

2. Maeda, Y., Tano, E., Makino, H., Konishi, T. and Ishii, I., Evaluation of a GPS-based Guidance System for Visually Impaired Pedestrians. Technology and Persons with Disabilities Conference 2002, Los Angeles, California, USA, March 18-23, 2002.

3. May, M. Accessible GPS Navigation and Digital Map Information for Blind Consumers. ICWC 2000.

4. Strothotte, T., Fritz, S., Michel, R., Raab, A., Petrie, H., Johnson, V., Reichert, L. and Schalt, A., Development of Dialogue Systems for the Mobility Aid for Blind People: Initial Design and Usability Testing. ASSETS ’96, Vancouver, British Columbia, Canada, 139-144, 1996.

5. Golledge, R.G., Klatzky, R.L., Loomis, J.M., Speigle, J. and Tietz, J., A geographical information system for a GPS based personal guidance system, International Journal of Geographical Information Science, 12 (7), 727-749, 1998.

6. Franklin, N., Language as a means of constructing and conveying cognitive maps. In Portugali, J. (ed), The construction of cognitive maps. Kluwer Academic Publishers, 275-295, 1995.

7. Pitt, I.J. and Edwards, A.D.N., Improving the usability of speech-based interfaces for blind users. 2nd annual ACM conference on Assistive technologies, Vancouver, Canada, April 1996. 124 130, 1996. 
8. Ross, D.A. and Blasch, B.B., Evaluation of Orientation Interfaces for Wearable Computers. ISWC'00. 2000.

9. Sabelman, E.E., Burgar, C.G., Curtis, G.E., Goodrich, G., Jaffe, D.L., Mckinley, J.L., Van Der Loos, M. and Apple, L.G., Personal navigation and wayfinding for individuals with a range of disabilities, Project report: Device development and evaluation. http://guide.stanford.edu/Publications/dev3.html, 1994.

10. Dodson, A.H., Moore, T. and Moon, G.V. A Navigation System for the Blind Pedestrian, GNSS 99, Genoa, Italy, 513-518, 1999.

11. Helal, A.S., Moore, S.E. and Ramachandran, B., Drishti: An integrated Navigation System for Visually Impaired and Disabled. 5th International Symposium on Wearable Computers, Zurich, Switzerland, 2001.

12. Petrie, H., User requirements for a GPS-based travel aid for blind people. In Gill, J.M. and Petrie, H. (eds), Orientation and Navigation Systems for Blind Persons, UK, 1-2 February. RNIB. 1995.

13. Kay L., Air sonar with acoustical display of spatial information. In Busnel, R.G. and Fish, J.F., Animal Sonar System, Plenum Press, New York, 769-816, 1980.

14. Bradyn, J.A. A review of mobility aids and means of assessment. In Warren, D.H. and Strelow, E.R. (eds.), Electronic spatial sensing for the blind. Martinus Nijhoff, 13-27, 1985.

15. Fruchterman, J., Archenstone's orientation tools: Atlas Speaks and Strider. In Gill, J.M. and Petrie, H. (Eds.). Orientation and Navigation Systems for Blind Persons, Hatfield, UK. 1-2 February 1995. RNIB. 1995.

16. Kemmerling, M. and Schliepkorte, H., An Orientation and Information System for Blind People based on RF-Speech-Beacons. TIDE, Helsinki, July 1998.

17. Ertan, S., Lee, C., Willets, A., Tan, H. and Pentland, A., A Wearable Haptic Navigation Guidance System. 2nd International Symposium on Wearable Computer, Pittsburgh, PA, 164165, 1998.

18. Golding, A. R. and Lesh, N., Indoor navigation using a diverse set of cheap, wearable sensors. Third International Symposium on Wearable computers, San Francisco, CA, 29-36, 1999.

19. Long, S., Aust, D., Abowd, G.D. \& Atkeson, C., Cyberguide: Prototyping Context-aware Mobile Applications. In CHI '96 Conference Companion, p.293-294, 1996.

20. Loomis, J.M., Golledge, R.G. and Klatzky, R.L., GPS-Based Navigation System for the Visually Impaired. In Barfield, W. and Caudell, T. (Eds.), Fundamentals of Wearable Computers and Augmented Reality. Mahwah NJ: Lawrence Erbaum Associates, 429-446, 2001.

21. Downs, R.M. \& Stea, D. Cognitive Maps and spatial behaviour: Process and Products. In R.M. Downs and D. Stea (Eds,), Image and Environment (pp. 8-26). Chicago: Aldine, 1997.

22. Jonsson, E., Inner Navigation: why we get lost and how we find our way. Scribner, New York, 27-126, 2002.

23. Kitchin, R.M., Blades, M. \& Golledge, R.G. Understanding spatial concepts at the geographic scale without the use of vision”. Progress in Human Geography, 21, 2: 225-242, 1997b.

24. Kitchen, R.M. \& Jacobson, D. Techniques to collect and analyze the cognitive map knowledge of people with visual impairments or blindness: Issues of validity. Journal of Visual Impairment and Blindness. July-August, 360-376, 1997.

25. Zetie, C., Market Overview: The emerging Context-Aware Software Market, Unwired Express website, http://www.unwiredexpress.com.

26. Dey, A.K. and Abowd, G.D, Towards a Better Understanding of Context and ContextAwareness. CHI 2000 Workshop on The What, Who, Where, When, and How of ContextAwareness, The Hague, Netherlands, 2000.

27. Bradley, N.A. and Dunlop, M.D., Investigating context-aware clues to assist navigation for visually impaired people. Workshop on Building Bridges: Interdisciplinary Context-Sensitive Computing, University of Glasgow, Scotland, $9^{\text {th }}$ September 2002, 5-10, $2002 \mathrm{a}$.

28. Pascoe, J. Adding Generic Contextual Capabilities to Wearable Computers. Proc. of $2^{\text {nd }}$ International Symposium on Wearable Computers, 92-99, 1998.

29. Kitchin, R.M., Blades, M. \& Golledge, R.G. Relations between psychology and geography. Environment and Behavior 29, 4: 554-573, 1997a.

30. LaGrow, S. and Weessies, M., Orientation \& Mobility: Techniques for Independence. The Dunmore Press Limited, New Zealand, p.9, 1994.

31. Bradley, N.A. and Dunlop, M.D., Understanding contextual interactions to design navigational context-aware applications. Mobile HCI, Pisa, 18-20 ${ }^{\text {th }}$ September 2002, p.349-354, 2002b.

32. Hart, S. and Staveland, L., Development of NASA-TLX (Task Load Index): Results of empirical and theoretical research. In Hancock, P. and Meshkati, N. (Ed.), Human mental workload, North Holland B.V., 139-183, 1988. 
33. Bradley, N.A.; Dunlop, M.D. Towards a multidisciplinary user-centric design framework for context-aware applications. $1^{\text {st }}$ UK-UbiNet Workshop, Imperial College London. $25^{\text {th }}-26^{\text {th }}$ September 2003.

34. Dey, A.K., Salber, D. \& Abowd, G.D. A conceptual framework and a toolkit for supporting the rapid prototyping of context-aware applications. Human Computer Interaction Journal, 16, 2001. Special issue.

35. Schilit, B., Adams, N. \& Want, R. Context-Aware Computing Applications. First International Workshop on Mobile Computing Systems and Applications. p.85-90. 1994.

36. Schilit, B. \& Theimer, M. Disseminating Active Map Information to Mobile Hosts. IEEE Network. Vol. 8(5). p.22-32. 1994.

37. Dourish, P. Seeking a Foundation for Context-Aware Computing. Journal of Human-Computer Interaction. Vol. 16 (2-4). 2001. 